\title{
The Males of Rhynchomicropteron (Diptera: Phoridae)
}

\author{
by
}

\section{R. H. L. Disney ${ }^{1}$}

The genus Rhynchomicropteron Annandal (1912) has distinctive, myrmecophilous, flightless females. The females of the 17 Oriental species are keyed by Disney \& Kistner (1998), supplemented by Disney (1999, 2010). Until Brown (1992) reared $R$. nudiventer Papp in Thailand, the males had been assigned to the genus Gymnoselia Schmitz (1927). This 'genus' contained the type species, $R$. curvescens (Schmitz 1927) and $R$. nudicosta (Brues 1907). Neither of these have been linked to their females. Recently Lengyel (2011) has described both sexes of a species from Israel, and reported the presence of this genus in Africa and Australia. The males remain poorly known. The purpose of this paper is to provide a key to the known males, even though most remain unknown and some are given code numbers only until they can be linked to their females.

An initial impediment has been the recognition of Schmitz's species, $R$. curvescens. Subsequent to his initial description, Schmitz (1929) provided a more detailed description in which he included the statement that its palps are dark brown ('dunkelbraun'). However, all the males I have examined, and $R$. nudicosta, have dusky yellow or yellow palps. In view of this I have borrowed its holotype of $R$. curvescens, kindly loaned by Dr Thomas Pape (Natural History Museum of Denmark, Copenhagen). I have remounted it on a slide. Its palps are clearly not dark brown, but are a slightly dusky yellow.

The females of the $R$. nudiventer are largely recognised from negative characters. Furthermore it is the most widely distributed species and is somewhat variable. It may prove to be a sibling species complex. The procurement of mating pairs, reared series or molecular barcodes will eventually provide an answer. However, I have compared its holotype female with a female from Brown's reared series (Disney 2010). Furthermore, Chris von Beeren recently sent me a reared series of $R$. nudiventer from Malaysia that has allowed a detailed scrutiny of the details of its male.

\footnotetext{
${ }^{1}$ Department of Zoology, University of Cambridge, Downing Street, Cambridge CB2 3EJ, U.K. Email: rhld2@hermes.cam.ac.uk
} 


\section{NOTES ON THE KNOWN MALES}

\section{Rhynchomicropteron curvescens (Schmitz)}

The holotype is from Java.

Rhynchomicropteron nudicosta (Brues)

The holotype from India has been lost, but the original description indicates that its legs are reddish brown rather than the yellow of all other known males.

\section{Rhynchomicropteron kuslitzkyi Lengyel}

The type series is from Israel.

Rhynchomicropteron nudiventer Papp

The holotype female was from N. E. India. The male was described by Brown (1992) from Thailand. Females attributed to this species are also known from Borneo and Malaysia.

Rhynchomicropteron Species 1

A male from Malaysia collected with females of $R$. nudiventer at a colony of Aenictus sp. was attributed to this species (Disney 1992), but it was later found to differ from Brown's (1992) description of the male of this species (Disney 2010).

\section{Rhynchomicropteron Species 2}

A male from Malaysia collected with females of $R$. necaphidiforme Disney and $R$. nudiventer at a colony of Leptogenys distinguenda (Emery) (Disney 1992) is probably $R$. necaphidiforme.

Rhynchomicropteron Species 3

A male from Malaysia was collected in a pitfall trap along with males of $R$. nudiventer and a female of $R$. beaveri (Disney).

Rhynchomicropteron Species 4

A male from a trap in Indonesia, Sulawesi.

\section{KEY TO KNOWN MALES OF RHYNCHOMICROPTERON}

Caution.The following key covers less than half the species known as females.

1. Legs yellow

- Legs brown nudicosta (Brues)

2. Costa with minute costal cilia along most of length (e.g. Figs $9 \& 13$, see appendix) 
- Costa seemingly lacking costal cilia (as any are less than $0.02 \mathrm{~mm}$ long and are therefore not apparent at $\times 100$ or less) (Figs 1, 5 and 17), but a few may be evident near base (Fig. 6).

3. Mesopleuron with fewer than 20 hairs. Frons with fewer than 40 hairs...

- Mesopleuron with more than 20 hairs. Frons with more than 60 hairs. (Hypopygium as Figs. 8a \& 8b in Lengyel 2011) ......... kuslitzkyi Lengyel

4. Frons with less than 20 hairs (Fig. 16). (Hypopygium as Figs $14 \& 15$ )...

Species 2

- Frons with more than 20 hairs ......................................................................5

5 Frons with a median furrow (Fig. 12). Mesopleuron with more than 8 hairs. Hypopygium as Figs. 10 and 11 ............................................Species 1

- Frons without a median furrow. Mesopleuron with less than 8 hairs. Hypopygium as Figs 21 and 22 ..............................................................Species 4

6 Anterolateral bristles present and almost as close to eye margins as mediolaterals (e.g. Figs. 8 \& 20).

- Annterolaterals absent (Fig. 4). (Hypopygium as Figs. 2 \& 3).

curvescens (Schmitz)

7. Frons with more than 40 hairs (Fig. 8). Hypopygium as Fig. 7. nudiventer Papp

- Frons with less than 40 hairs (Fig. 20). Hypopygium as Figs 18 and 19 ... Species 3

\section{ACKNOWLEDGMENTS}

I am grateful to Dr Thomas Pape (Natural History Museum of Denmark, Copenhagen) for the loan of the holotype material of $R$. curvescens. My studies of Phoridae are currently supported by grants from the Balfour-Browne Trust Fund (University of Cambridge) and the Systematics Research Fund of the Linnean Society and the Systematics Association (UK).

\section{REFERENCES}

Annandale, N. 1912. Description of a micropterous fly of the family Phoridae associated with ants. Spolia Zeylanica, Colombo 8: 85-89.

Brown, B. V. 1992. Life history, immature stages and undescribed male of Rhynchomicropteron (Diptera: Phoridae). Journal of Natural History 26: 407-16. 
Brues, C. T. 1907. Some new exotic Phoridae. Annales Musei Nationalis Hungarici 5: 400413 + Plate VIII.

Disney, R. H. L., 1992. A further new species of Rhynchomicropteron (Dipt., Phoridae) from Malaysia. Entomologist's Monthly Magazine 128: 219- 224.

Disney, R. H. L., 1999. Two new species of Rhynchomicropteron (Diptera:Phoridae) from Borneo. Sociobiology 34: 429-432.

Disney, R. H. L., 2010. Newly recognised sibling species of Rhynchomicropteron nudiventer (Diptera: Phoridae). Sociobiology 56: 249-253.

Disney, R. H. L. \& Kistner, D. H., 1998. New species and new records of myrmecophilous Phoridae (Diptera). Sociobiology 31: 291-349.

Lengyel, G. B., 2011. The first Rhynchomicropteron Annandale, 1912 (Diptera, Phoridae) species from the Palearctic region with taxonomic and faunistic notes on the fauna of Israel. Zootaxa 2885: 23-32.

Schmitz, H. 1927. Revision der Phoridgattungen, mit Beschreibung neuer Gattungen und Arten. Natuurhistorisch Maandblad 16, 30-40, 45-50, 59-68,72-79, 92-100, 110-116, 128-132, 142-148, 164, 176.

Schmitz, H. 1929. Revision der Phoriden. Berlin: Ferd. Dummlers. 212 pp + Tafel I and II.

\section{APPENDIX}

Figures 1-22

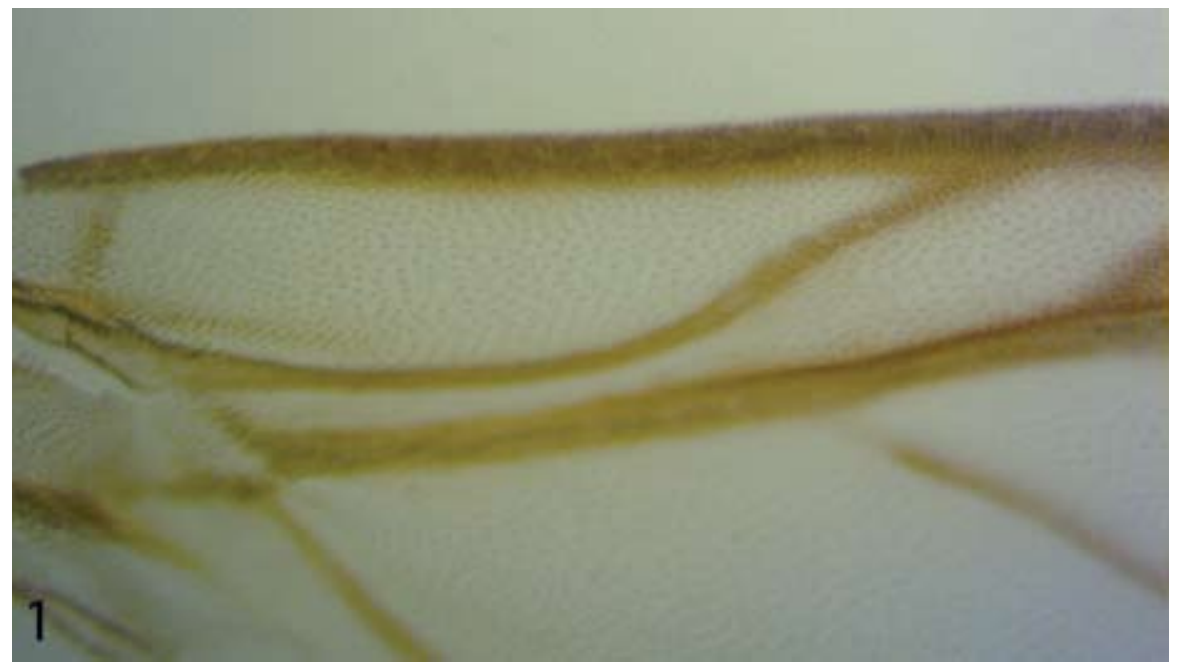

Fig. 1. Rhynchomicropteron curvescens male, costal section 1 . 


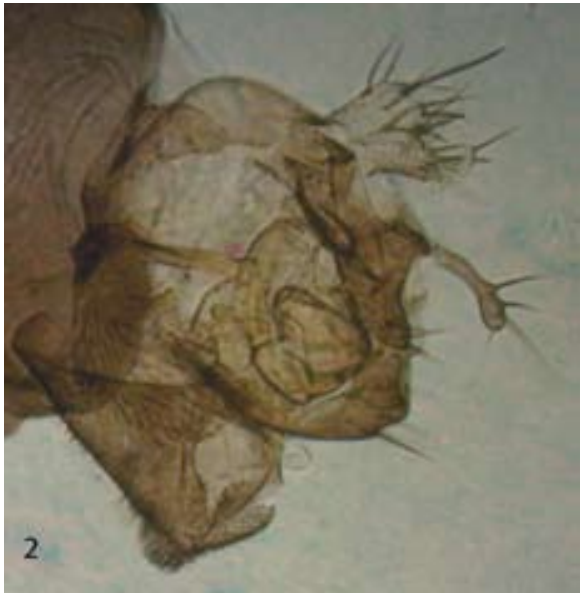

Fig. 2. Rhynchomicropteron curvescens male, left face of hypopygium.

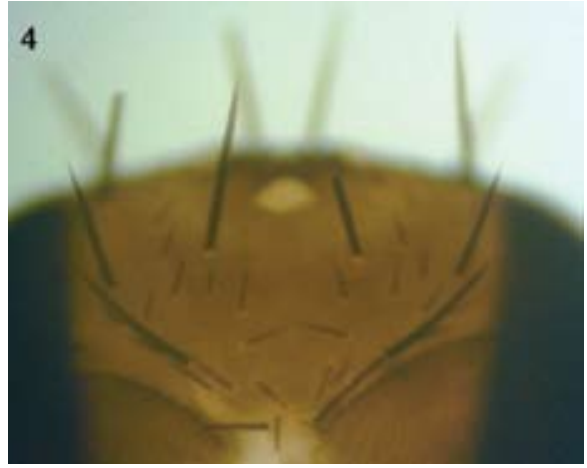

Fig. 4. Rhynchomicropteron curvescens male, frons.

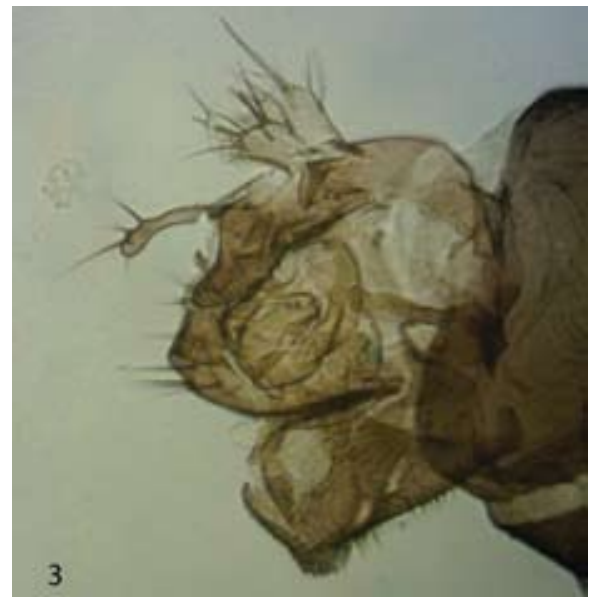

Fig. 3. Rhynchomicropteron curvescens male, right face of hypopygium.

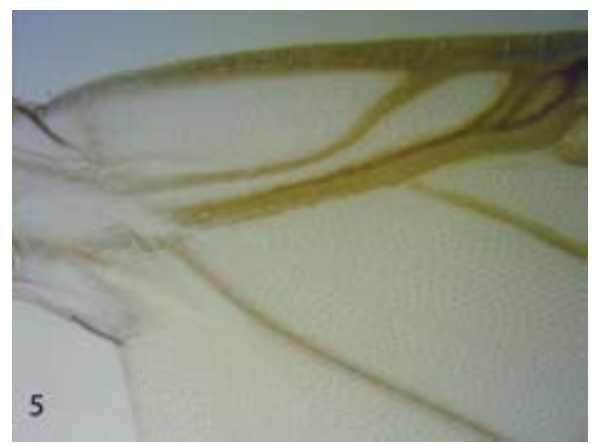

Fig. 5. Rhynchomicropteron nudiventer male, costal section 1 .

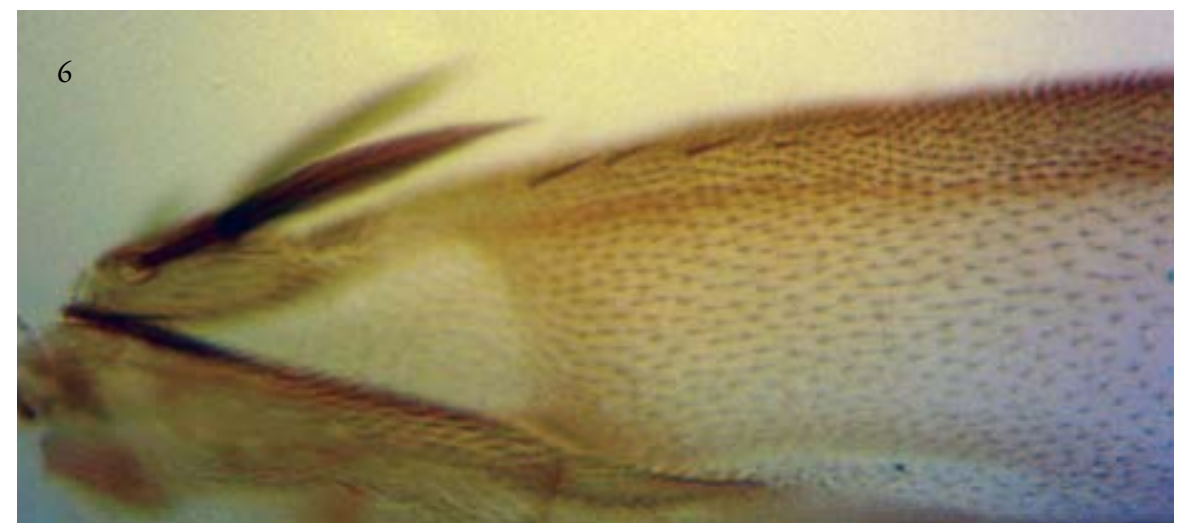

Fig. 6. Rhynchomicropteron nudiventer male, costal section 1, with a few costal cilia at base. 


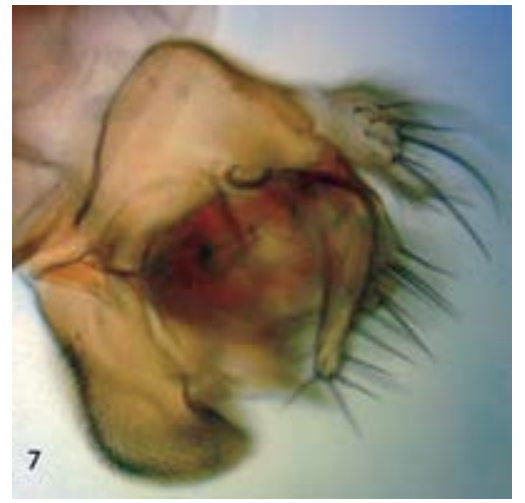

Fig. 7. Rhynchomicropteron nudiventer male, left face of hypopygium.

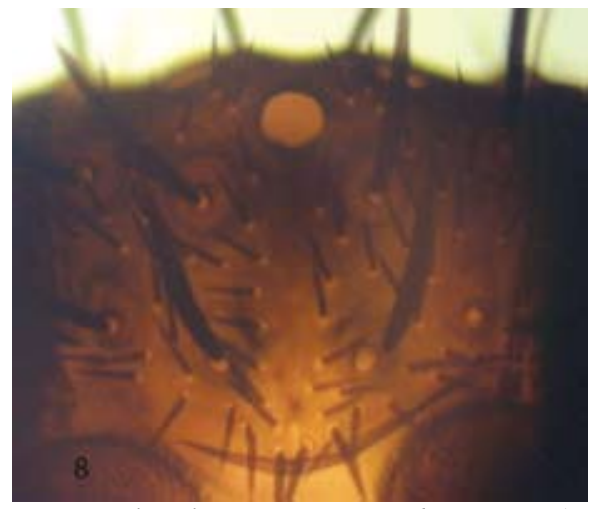

Fig. 8. Rhynchomicropteron nudiventer male, frons.

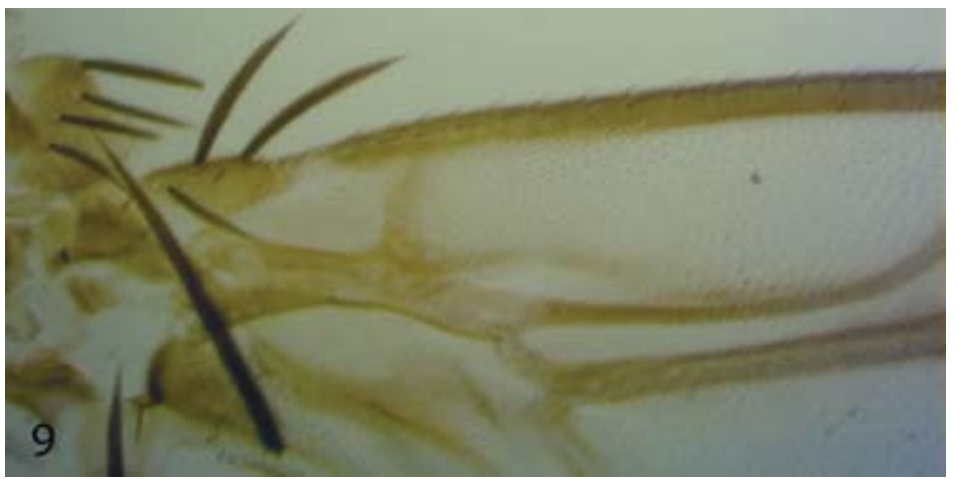

Fig. 9. Rhynchomicropteron species 1 male, costal section 1 .

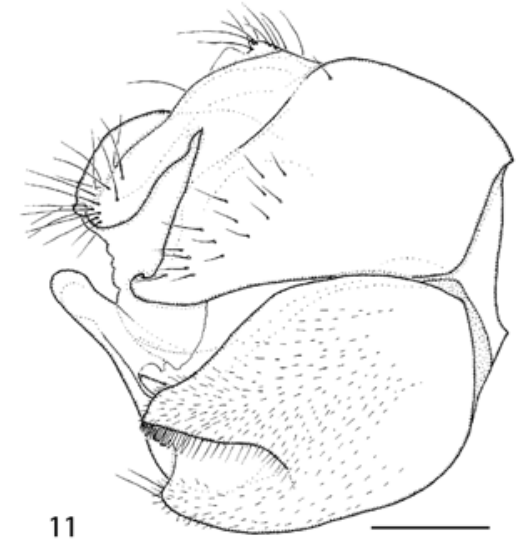

Fig. 11. Rhynchomicropteron species 1 male, right face of hypopygium. (Scale bar=0.1 $\mathrm{mm}$ ).

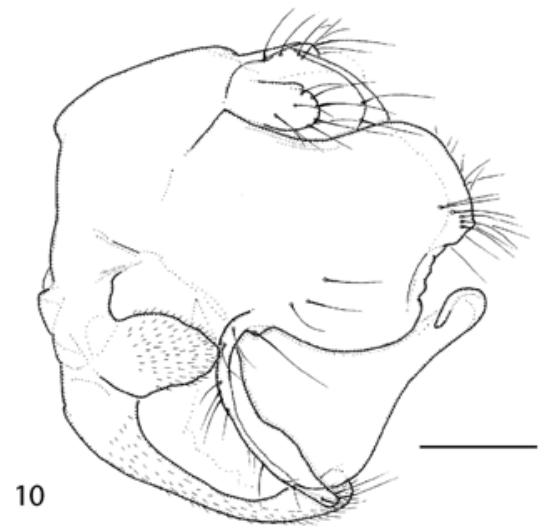

Fig. 10. Rhynchomicropteron species $1 \mathrm{male}$, left face of hypopygium. (Scale bar $=0.1 \mathrm{~mm}$ ). 


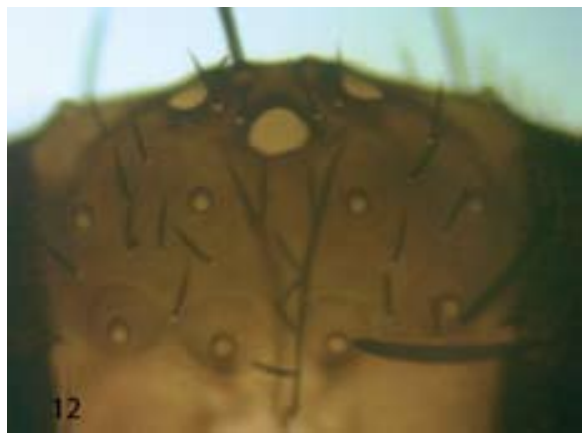

Fig. 12. Rhynchomicropteron species 1 male, frons

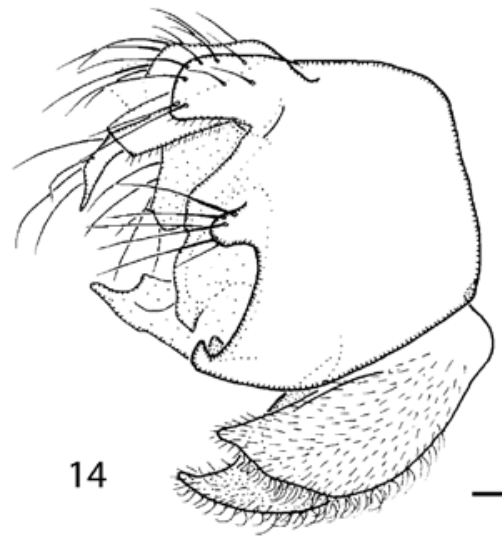

Figs 14-15. Rhynchomicropteron species 2 male, hypopygium. Fig. 14. Right face; Fig. 15. Left face. (Scale bar $=0.1 \mathrm{~mm}$ ).

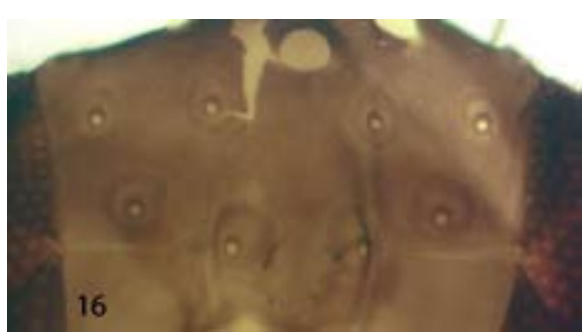

Fig. 16. Rhynchomicropteron species 2 male, frons.

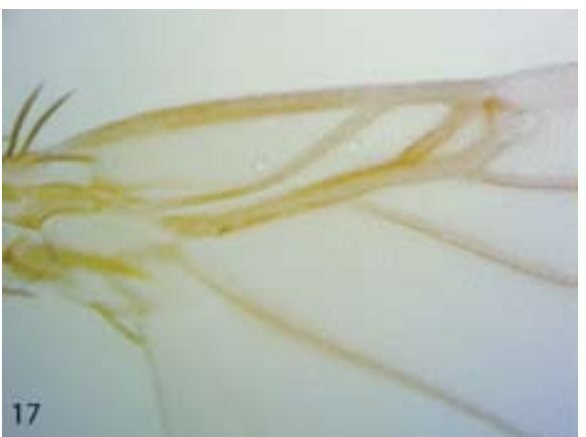

Fig. 17. Rhynchomicropteron species 3 male, costal section 1 . 


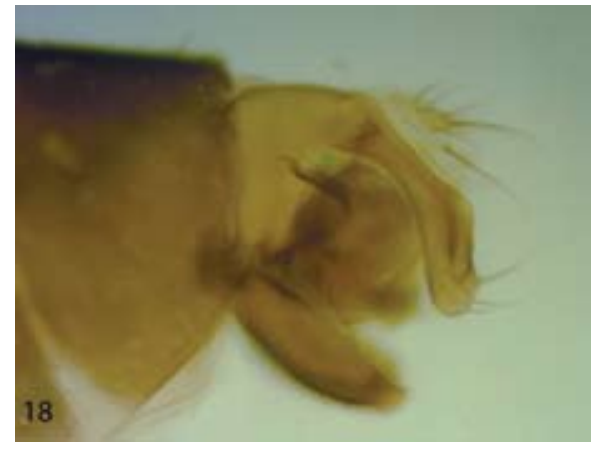

Fig. 18. Rhynchomicropteron species 3 male, left face of hypopygium.

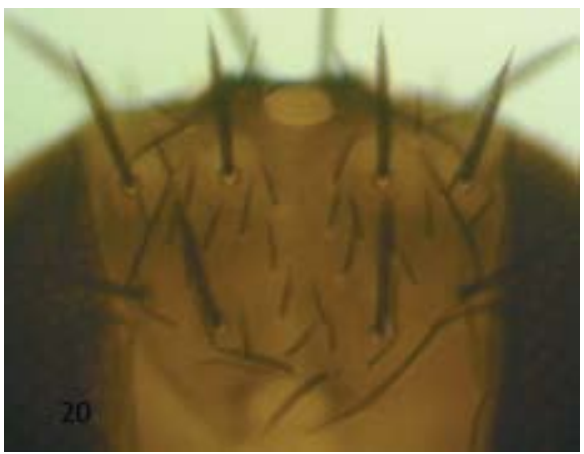

Fig. 20. Rhynchomicropteron species 3 male, frons.

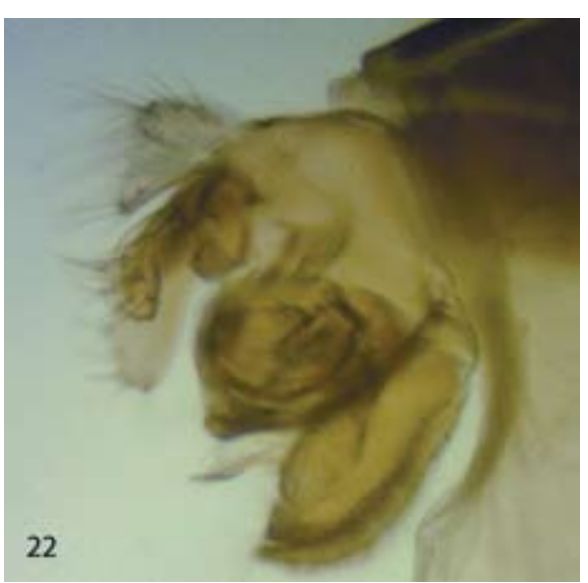

Fig. 22. Rhynchomicropteron species 4 male, right face of hypopygium.

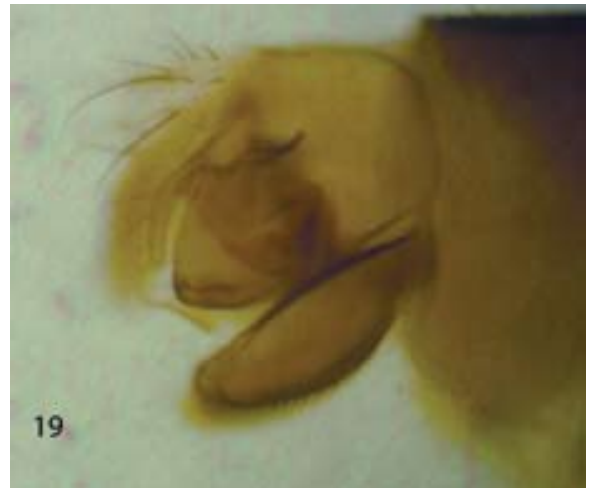

Fig. 19. Rhynchomicropteron species 3 male, right face of hypopygium.

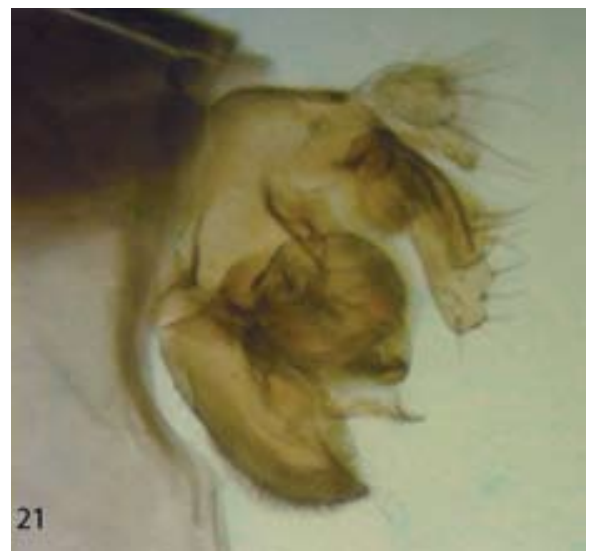

Fig. 21. Rhynchomicropteron species 4 male, left face of hypopygium. 